\title{
Finite Element Modeling of Reinforced Concrete Column under Monotonic Lateral Loads
}

\author{
Shams Al-Amin \\ Lecturer, Department of Civil Engineering, Ahsanullah \\ University of Science and Technology \\ 141-142, Tejgaon I/A, Dhaka-1208
}

\author{
Raquib Ahsan \\ Professor, Department of Civil Engineering, \\ Bangladesh University of Engineering and Technology, \\ Dhaka-1000
}

\begin{abstract}
The response of reinforced concrete columns under lateral load has always been an area attracting research and practical interest. The importance of columns in building frame in terms of lateral stiffness has been subjected to growing attention in relation to soft storey phenomena and other seismic response analysis over times. Various numerical approaches has been attempted to correlate deflection with lateral load according to theories and field performance. A numerical analysis has been carried out in this study on column behavior subjected to lateral load. Cantilever columns have been modeled using finite element analysis package ANSYS considering non linear stress-strain relationship of concrete and bilinear behavior of steel. Effect of lateral reinforcement in terms of confinement has also been associated. For simplicity of analysis, only rectangular columns with single story height have been considered. The results have been compared with field experimental data. The response of load-deflection curve to change in column geometry has also been discussed. The load deflection curve found in this manner is almost linear with constant stiffness initially as suggested by ACI in the elastic zone. However stiffness gradually decreases in the plastic zone and finally tends to zero. Column response to change in column geometry is also according to the prescribed relations in ACI. Increase in stiffness has been found with decrease in height and increase in cross section. Finally the test results are compared with field experimental value where they show almost similar behavior.
\end{abstract}

\section{General Terms}

Building Frame, RCC structures, Finite Element Method.

\section{Keywords}

Reinforced Concrete, FEM, ANSYS , Column

\section{INTRODUCTION}

Columns are defined as members that carry loads chiefly in compression. Never the less, their contribution in horizontal stiffness of building frames, is also of great importance. The main reinforcement in columns is longitudinal, parallel to the direction of the axial load, and consists of bars arranged in a square, rectangular or circular pattern. The design primarily considers the compression and bending moments about one or both axes of the cross section. When strong horizontal shaking, as one during an earthquake, is transmitted, the columns may undergo lateral deflection which in turn affects the horizontal stiffness and response of the frame greatly. The study of response of RCC columns under lateral load in terms of deflection is therefore, bears great importance.

The finite element method is a general technique for constructing solutions to boundary value problems. This method involves dividing the domain of interest into a finite number of simple sub domains, the finite elements, and using various concepts to construct an approximation of the solution over the collection of finite elements. FEM can overcome the basic assumption by ACI that plane section remains plane and can produce more realistic picture of material response to load. It can accommodate cracking and crushing phenomena of concrete to predict possible non linear response to load.

The behavior of RC columns under increasing load has been determined by many researchers . The objective of the study is to develop a computer program in ANSYS for analyzing the deflection of a column subjected to lateral load. The idea is to investigate load-deflection response in elastic zone as well as in plastic zone and to widen the scope of the program by including confinement effect due to lateral reinforcement.

\section{METHODOLOGY}

\subsection{Steps in Finite Element Program}

The ANSYS 10 program can undertake simple static analysis as well as complex non linear dynamic analysis. The first step is to build a finite element model which requires most of the time. PREP7 preprocessor is used to define the element types, element real constants, material properties and model geometry [1]. Load is applied in the next step and SOLUTION processor is to be used to define the analysis type and analysis. Once the solution has been calculated, post processor has to be used to review the results. The post processors are POST1 and POST26. POST1 is used to review results at one sub-step (time step) over the entire model or selected portion of the model [1]. POST26 is the time history postprocessor and is used to review results at specific points in the model over all time steps [1].

\subsection{Element types}

For representation the concrete, an eight node solid element SOLID 65 has been used. The solid element has eight nodes with three degrees of freedom at each node viz. translations in the nodal $\mathrm{x}, \mathrm{y}$ and $\mathrm{z}$ directions. The element has features of plastic deformation, cracking in three orthogonal directions, and crushing. The most important feature of this element is the treatment of the non linear properties. 
The internal reinforcement is modeled using three dimensional spar elements LINK 8 with plasticity. Two nodes are required for this element. Each node has three degrees of freedom, translation in the nodal $\mathrm{x}, \mathrm{y}$ and $\mathrm{z}$ directions. The element is capable of plastic deformation. Its properties are also discussed in the material properties.

\subsection{Failure Criteria of Concrete}

Concrete is a quassi-brittle material. it behaves differently in compression and tension. The stress-strain curve of concrete is linearly elastic up to 30 percent of the maximum compressive strength in compression [2]. After this point, the stress increases nonlinearly up to the maximum compressive strength. Beyond the maximum compressive strength, the curve into the softer region and eventually crushing failure occurs at a ultimate strain [2]. In tension, the stress-strain curve for concrete is approximately linearly elastic up to maximum tensile strength.

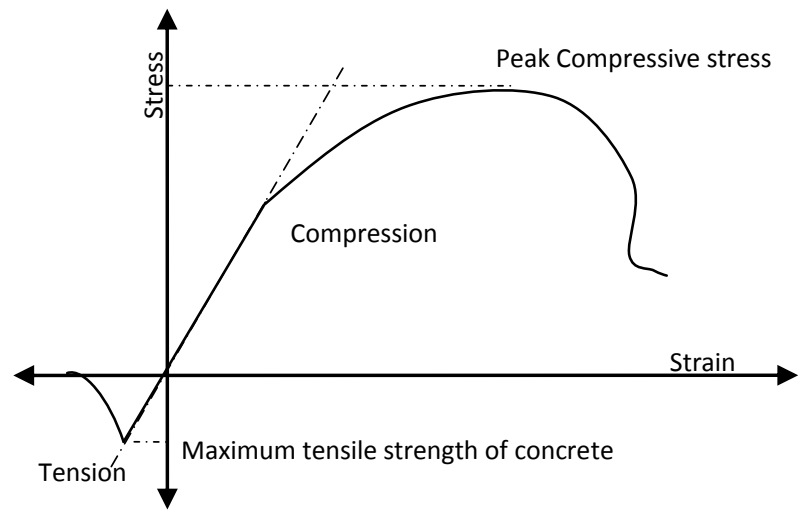

Fig 3: typical stress-strain curve of concrete

For concrete, ANSYS requires input data for Elastic modulus (E,), Ultimate uni-axial compressive strength, Modulus of rupture $f_{r}$ ) and Poisson's ratio ( $u$ ) [1]

For normal sand and stone concretes, $\mathrm{E}_{\mathrm{c}}$ is computed with reasonable accuracy from the empirical equation found in the ACI code [3],

$$
E,=57500 \sqrt{\mathrm{f}_{\mathrm{c}}^{\prime}}
$$

Modulus of rupture is calculated from [4]

$$
\mathbf{f}_{\mathrm{r}}=7.5 \sqrt{\mathrm{f}} / \mathrm{c}
$$

Poisson's ratio for concrete fall within the limits of 0.15 to 0.20 [5].

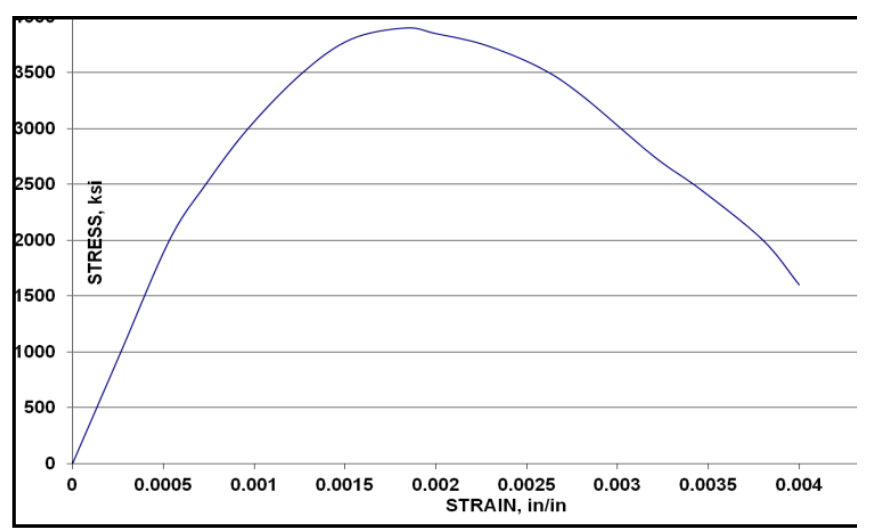

Fig: 4 Stress-Strain Curve Used In ANSYS

\subsection{Confined and Unconfined Concrete}

The material model for concrete used in this analysis is based on a model suggested by Cusson and Paultre( 1995) [6]. This model considers different stress-strain curves of concrete in zone confined by stirrup and concrete outside stirrup. An example of stress-strain curves for unconfined and confined concrete is shown in Figure 5.

In the confinement model suggested by Cusson and Paultre (1995), the confined concrete stress and strain are computed as

$$
\begin{aligned}
& f_{c c}=f_{c o}\left(1+2.1\left(\frac{f_{i e}}{f_{c o}}\right)^{0.7}\right) \\
& \epsilon_{c c}=\in_{c o}+0.21\left(\frac{f_{i e}}{f_{c o}}\right)
\end{aligned}
$$

Where eco and fco are determined from tests on $150^{\prime} 300 \mathrm{~mm}$ cylinders, and flelfco is the effective confinement ratio. The effective confinement ratio is a measure of the effectiveness of the confining steel configuration; the higher the value, the better the use of the confinement. This, in turn, means an enhancement of strength and ductility[6].

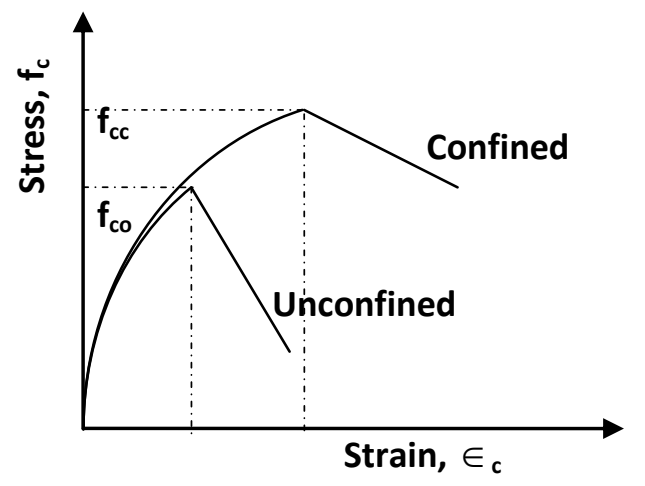

Fig 5: Stress-strain curves for confined and unconfined concrete [6]

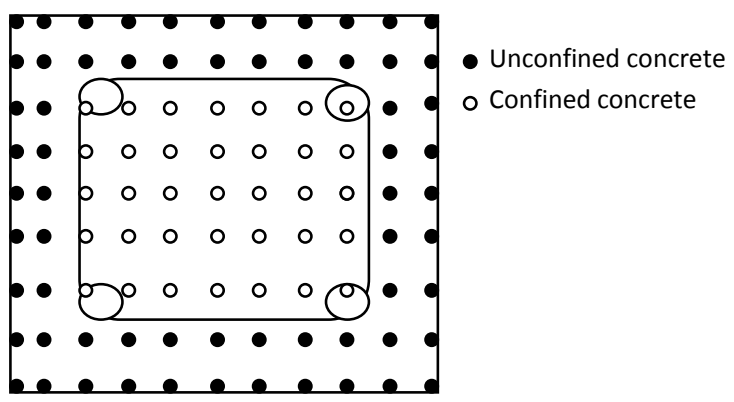

Fig 6: Confined and unconfined integration points in a column cross-section [6]

\subsection{Failure criteria of steel}

The steel for the finite element model is assumed as an elastic perfectly plastic material and identical in tension and compression. The properties, i.e., elastic modulus and yield stress, for the steel reinforcement used in this study follow the design material properties used for the experimental investigation. Poisson's ratio was assumed 0.3 for this study. 


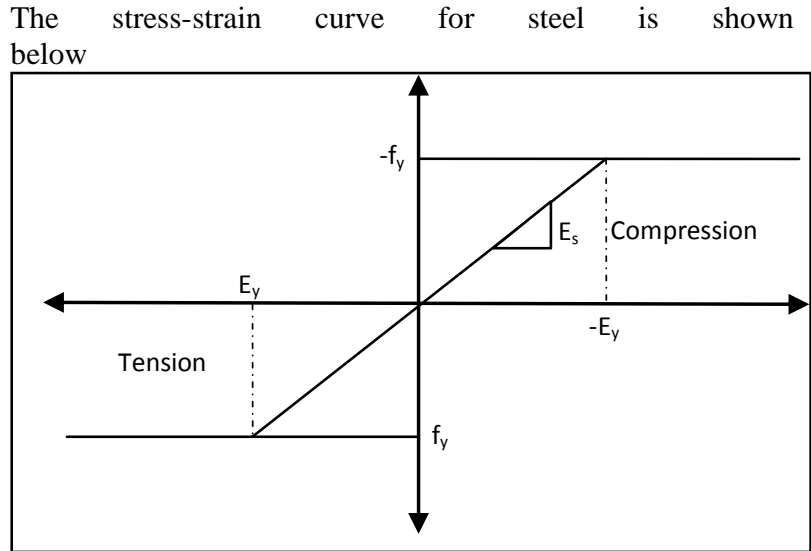

Fig: 7 stress strain curve of steel

\subsection{Mesh Sensitivity}

Mesh size plays an important role in Finite Element Method. A suitable mesh size is to be chosen to achieve sufficient accuracy and at the same time not to lengthen the runtime too long. Mesh size can vary in the analysis of a single structure [7]. Different mesh alignments generally give slightly varying solutions. In fact in real life problems mesh size is constantly refined to get a representative solution.

According to the literature of Finite Element Method the smaller are the elements, the better solution is. But this too has practical constraints because a very small mesh may require tremendous computational effort which may result an abnormally large runtime. Moreover, the result values does not show significant variation after a certain extent of refinement. It is to be noted also that no mesh is usually the ultimate one. The objective is to select a mesh size that produces a representative result. A mesh optimization test was carried out to understand the member response to varying number of elements

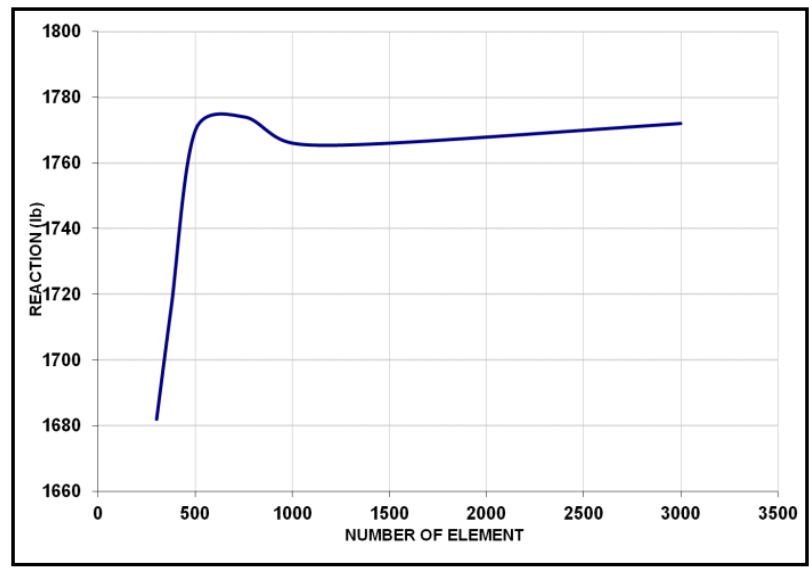

Fig 8: Effect of Meshing On Test Values

Based on the response of the member and considering the calculation time required element size of 2 inch $\times 2$ inch $\times 2$ inch is chosen.

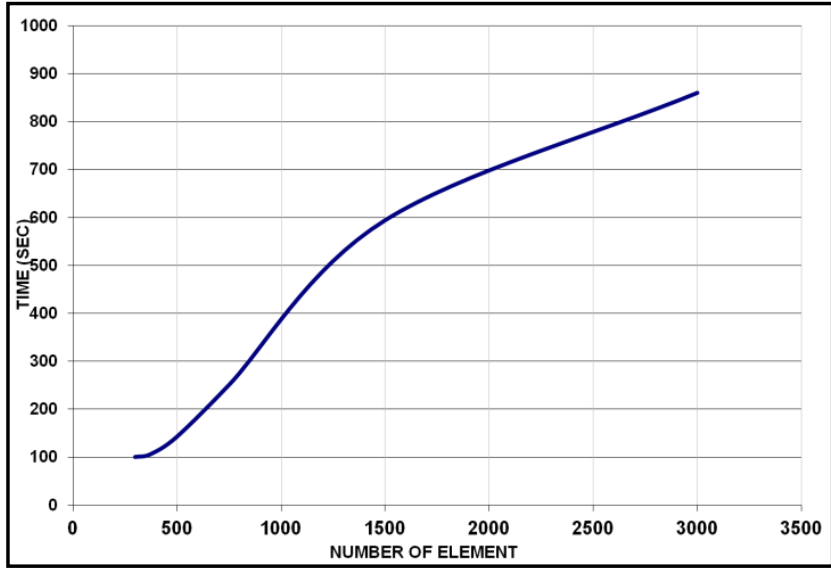

Fig 9: Effect Of Meshing On Calculation Time

Modeling of material non linearity is very complex for reinforced concrete structures [8]. After considering all the factors discussed above a complete model of reinforced concrete column is put under test for nonlinear analysis to predict the deflection of column subjected to lateral load at top. Different parametric studies were systematically carried out to assess the sensitivity of the adopted models in predicting the ultimate capacity. The size of the column and the amount of reinforcement were varied. It is necessary to confirm the reliability of the developed model. To ensure the accuracy of the model generation the behavior of the model must be checked against any known conditions.

\subsection{Column Geometry}

Column descriptions are given below

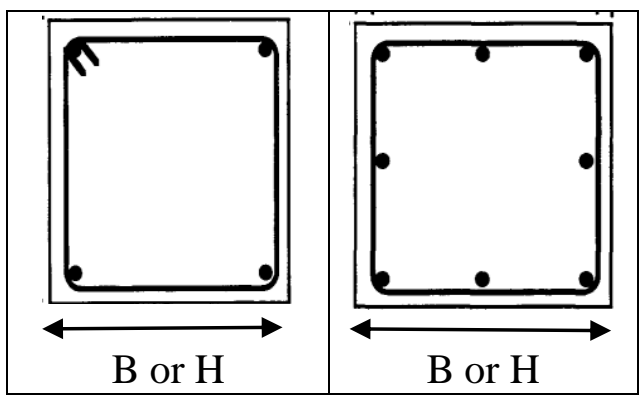

Fig 9: Column Geometry

Table 1 Geometry of analyzed columns

\begin{tabular}{|c|c|c|c|c|}
\hline MODEL & $\begin{array}{c}\text { B } \\
\text { (Inch) }\end{array}$ & $\begin{array}{c}\text { H } \\
\text { (inch) }\end{array}$ & $\begin{array}{c}\mathbf{L} \\
\text { (ft) }\end{array}$ & $\begin{array}{c}\text { No of } \\
\text { Bars }\end{array}$ \\
\hline 1 & 10 & 10 & 10 & 4 \\
\hline 2 & 12 & 12 & 10 & 4 \\
\hline 3 & 14 & 14 & 10 & 4 \\
\hline 4 & 10 & 10 & 10 & 8 \\
\hline 5 & 12 & 12 & 10 & 8 \\
\hline 6 & 14 & 14 & 8 & 8 \\
\hline
\end{tabular}




\section{RESULT AND DISCUSSION}

\subsection{Load-Deflection behavior}

Load deflection behavior found in the model 1 and 2 is shown below. All this models are generated with 4 bars. All three diagrams show a sudden slip at a certain load. All the columns undergo a slip at around 1.5 in a slip.

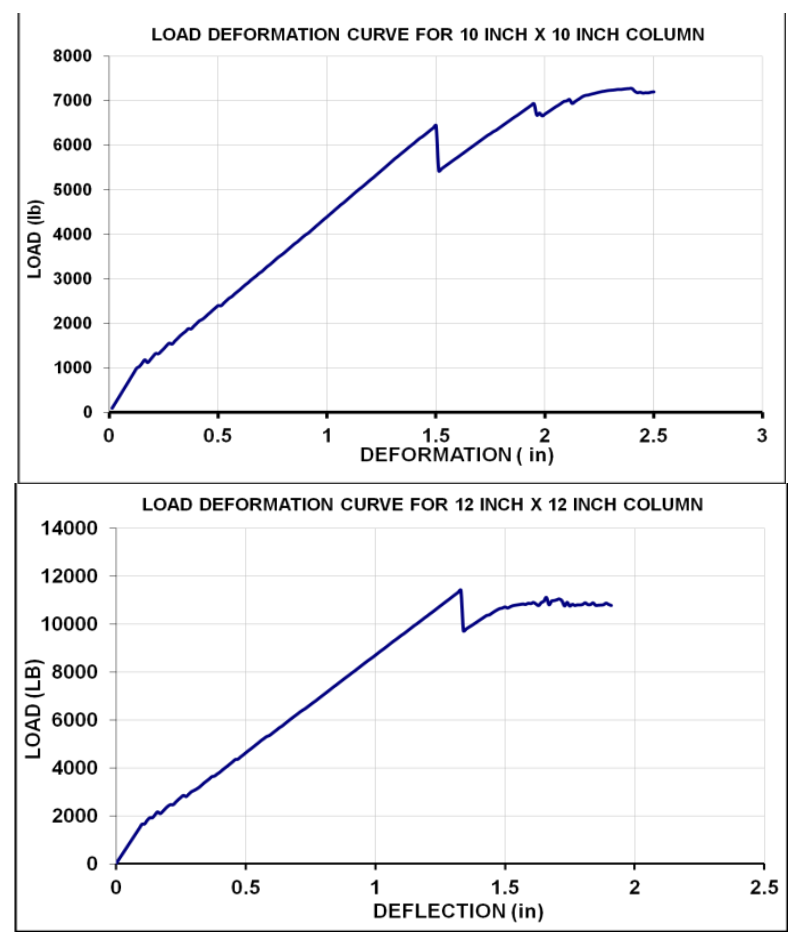

Fig 10: Load deflection curves of columns with 4 corner bars

Load deflection behaviour found in the model 6 is shown below. All this models $(4,5,6)$ are generated with 8 bars. The models suffer from non convergence at higher loads.

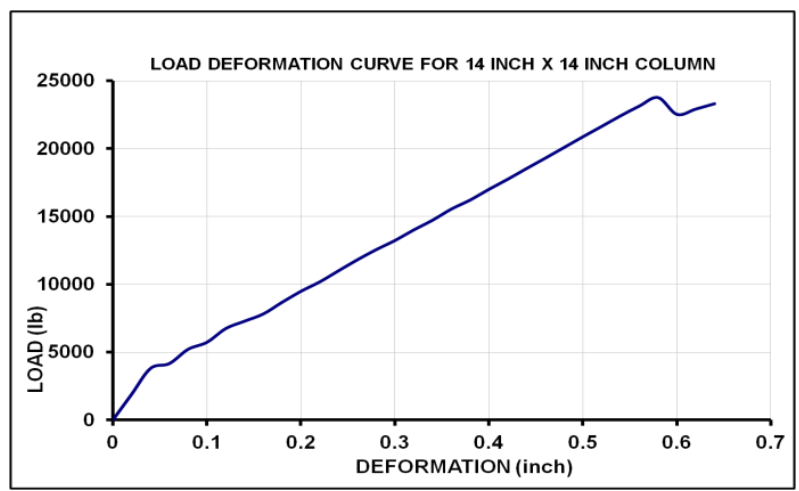

Fig 11: Load deflection curves of columns with 8 corner bars

\subsubsection{Discussion on load deflection behavior}

The cracking and crushing phenomena was analyzed using ANSYS which can show circles at locations of cracking or crushing in concrete elements. Cracking is shown with a circle outline in the plane of the crack, and crushing is shown with an octahedron outline. The first crack at an integration point is shown with a red circle outline, the second crack with a green outline, and the third crack with a blue outline.

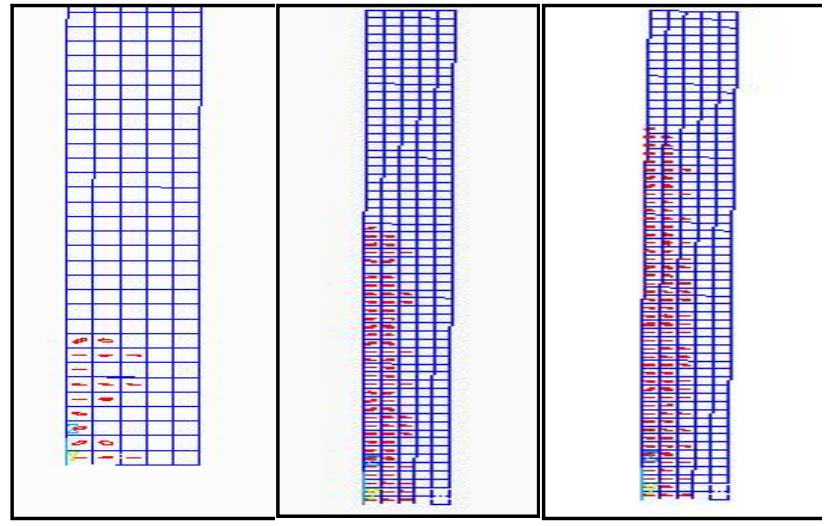

\section{deflection 0.2 deflection $0.5 \quad$ deflection 1 inch inch inch}

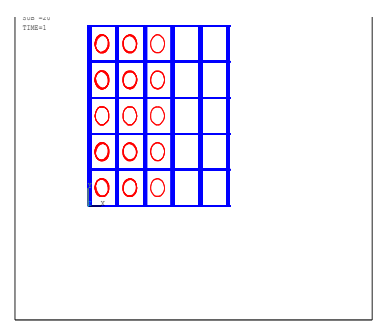

Fig 12: crack propagation with deflection

It was found that at smaller deflection tension cracks generates first at or near base and gradually propagates upward. At higher deflection (1 inch or higher in this case), crushing initiates at the compression side and also propagates upward .
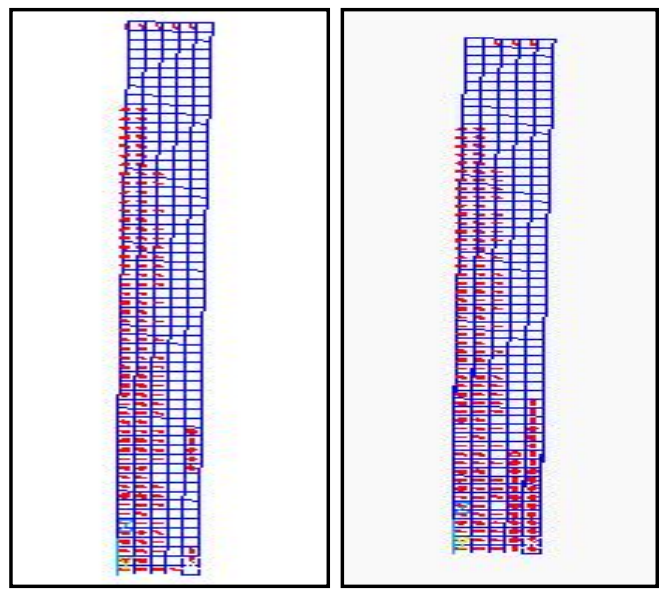

deflection 1.45 inch

deflection 1.55 inch

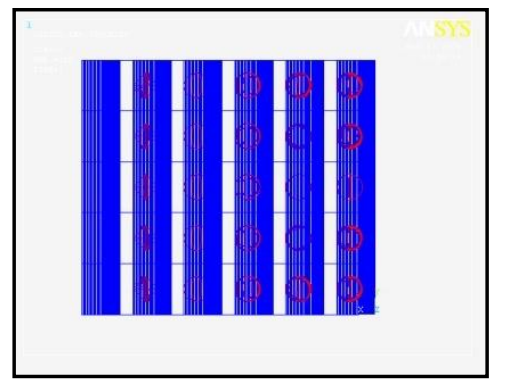

Fig 13: crushing in compression side 
The sudden fall in the 1.5 inch deflection could have happened due to the entire section deformation of concrete which may cause slip with lateral load applied. The crack propagation and fall patterns are same for different cross section but delays with an increase in cross sectional dimensions.

\subsection{Effect of Column Geometry on Load}

\section{Deflection Behavior}

Fig 14 to Fig 16 shows response of columns to change in column height, column cross section and change in percentage of reinforcement. As expected, column with larger heights undergo same deflection at a lower load value. (Fig 14). Again with increase in column cross section, columns are found to become more rigid and resulting less deflection (Fig $15)$.

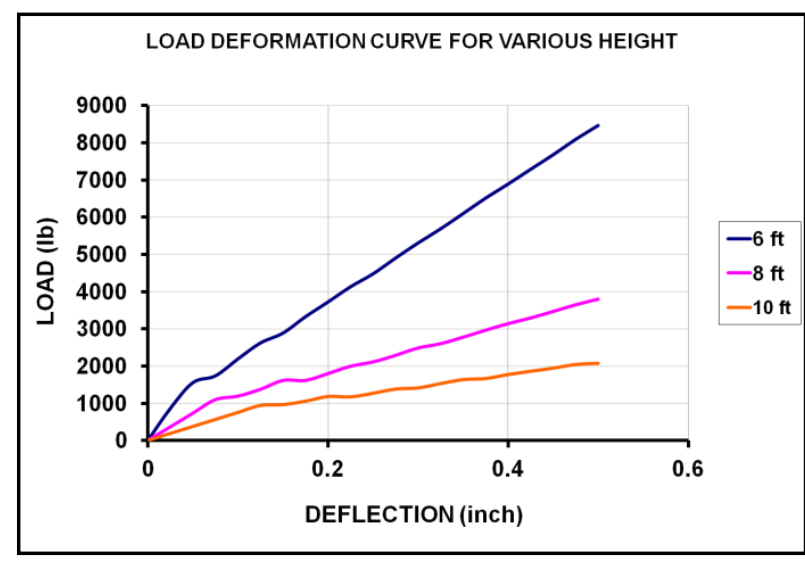

Fig 14: effect of column height on deflection

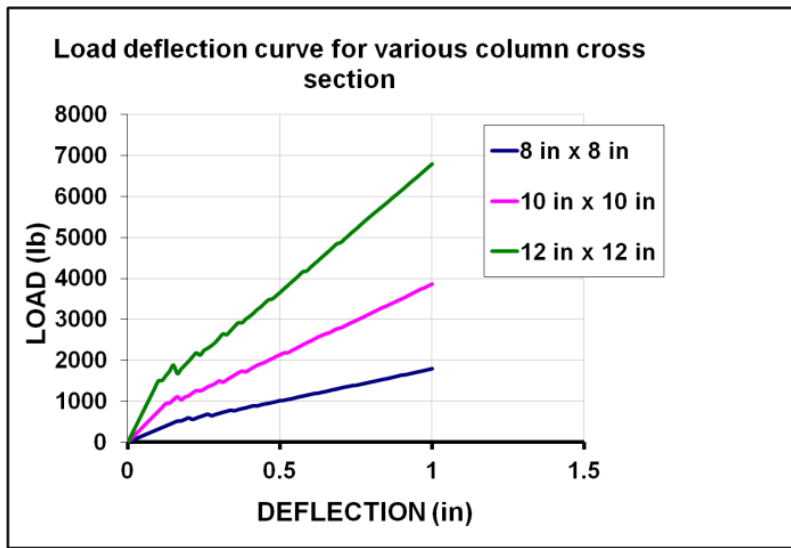

Fig 15: effect of column cross section on deflection

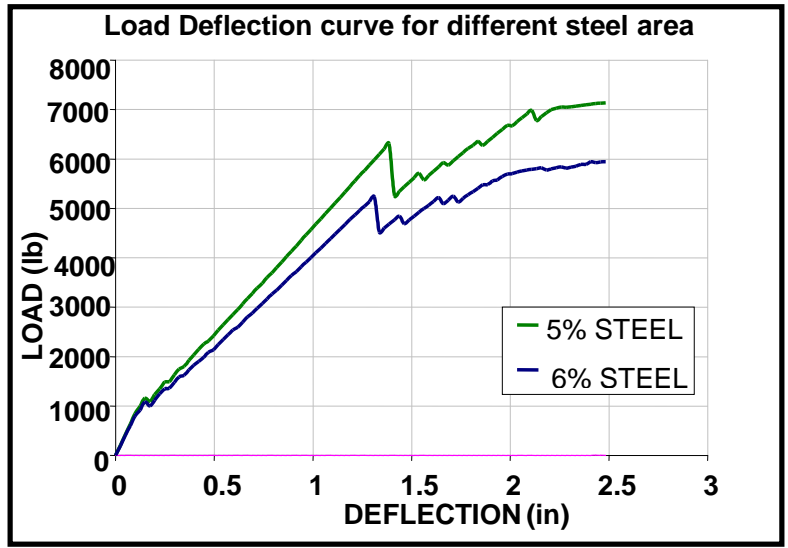

Fig 16: effect of steel area on deflection

Effect of steel area on column deflection is shown below. Columns with higher steel area are found to undergo less deflection at same load.

\subsection{Comparison with Experimental Data}

Experimental data was collected from National Institute of Standards and Technology (NIST), United States Department of Commerce Technology Administration. Using the data, a column was modeled with the same configuration to compare the experimental results with the ANSYS deflection prediction. The data series is taken from a cantilever specimen tested by Ohno, Tomonori; and Nishioka, Takashi (1984) [9].

Table 2 Specification of OHNO \& NISHIOKA (1984) Experimental Data

\begin{tabular}{|l|l|}
\hline HEIGHT OF SPECIMEN (L) & $1.6 \mathrm{~m}$ \\
\hline WIDTH OF SPECIMEN $(\mathrm{B}$ or $\mathrm{H})$ & $400 \mathrm{~mm}$ \\
\hline CONCRETE STRENGTH $\left(\mathrm{f}_{\mathrm{C}}^{\prime}\right)$ & $24.8 \mathrm{MPa}$ \\
\hline AXIAL LOAD $(\mathrm{P})$ & $157 \mathrm{KN}$ \\
\hline LONGI. REINFORCEMENT & $8 \mathrm{bars}$ \\
\hline LONGI. REINFORCEMENT DIA & $19 \mathrm{~mm}$ \\
\hline YIELD STRENGTH & $474 \mathrm{MPa}$ \\
\hline CLEAR COVER & $31.5 \mathrm{~mm}$ \\
\hline
\end{tabular}

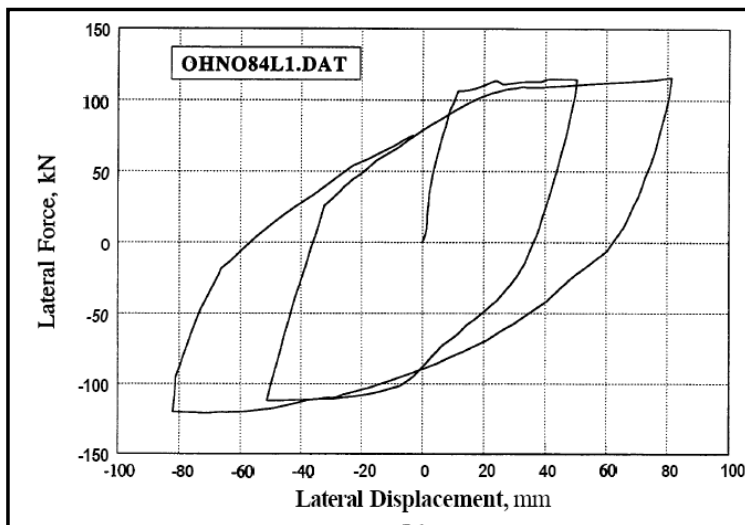

$$
\text { Fiqure 30. SpecimenL1 of Ohno } 1984
$$

Fig 17: curve based on experimental data

Program calculated values indicate good correlation with experimental values. The variation is within $10 \%$ up to $6 \mathrm{~mm}$. The program, however suffers from non convergence and cannot predict deflection beyond $6.23 \mathrm{~mm}$ deflection. The experimental data curve has a decreasing slop where as the 
program data has a sharp one, which indicates higher variations in upper deflections.

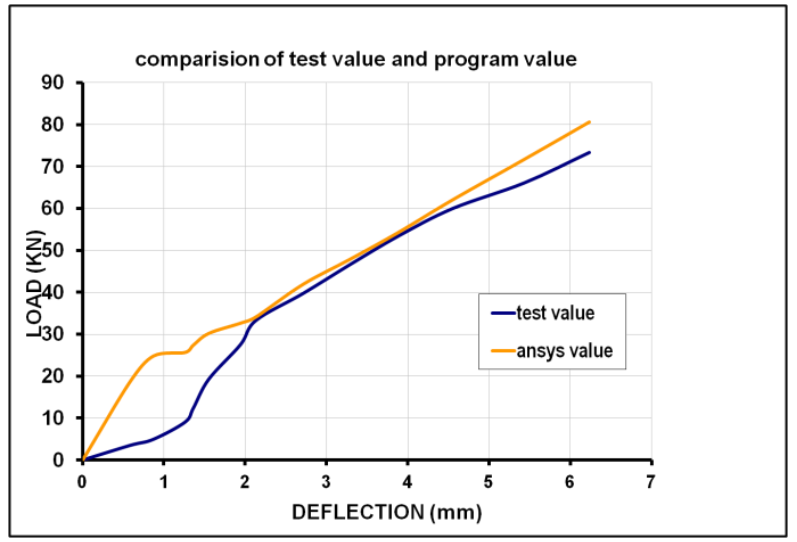

Fig 18: curve based on experimental data

\section{CONCLUSION}

The study was intended to investigate the possibilities of performing nonlinear finite element analysis of reinforced concrete column using ANSYS Package software. In view of the good correlation between the nonlinear finite element analysis models, it would seem that this numerical package can be used with confidence, both quantitatively and qualitatively. However more adjustments are yet to integrate to enable to predict the lateral load-deflection behavior more precisely. The deflection behavior of the column was carried out with limited extent. The model can predict stiffness quite accurately in the elastic zone. The relation between the applied load and lateral deflection is nearly linear in the elastic zone. Much research is needed in the future to comprehend the deflection characteristics of a column, especially in plastic zone.

\section{ACKNOWLEDGEMENT}

The study acknowledges the contribution of relevant studies [10], [11], [12] and also the contribution of ANSYS inc. for the wonderful analysis softwate developed.

\section{REFERENCES}

[1] ANSYS. 2005. ANSYS version 10 Manual Set 2005. ANSYS Inc., Southpointe, 275 Technology Drive, Canonsburg, PA 15317, USA.
[2] ASCE Task Committee on Concrete and Mesonary Structure. 1981, State of the Art Report on Finite Analysis of Reinforced Concrete, ASCE.

[3] American Concrete Institute. 1995. Building Code Requirements for Reinforced Concrete (ACI 318-95). Detroit.

[4] American Concrete Institute. 1999. Building Code Requirements for Reinforced Concrete (ACI 318-99). Detroit.

[5] Imran, I. and Pantazopoulou, S. 1996. Experimental study of plain concrete under triaxial stress. ACI Materials Journal, 1996. 93(6): p. 589-601.

[6] Cusson, D. and Paultre, P. 1995. Stress-strain model for confined high strength concrete. Journal of Structural Engineering. Vol 121, No 3, pp 468-477.

[7] Bathe, K. J. 1996. Finite Element Procedures, PrenticeHall, Inc., Upper Saddle River, New Jersey.

[8] Barzegar, F. and Maddipudi, S. 1997. Three-Dimensional Modeling of Concrete Structures. I: Plain Concrete. ASCE Journal of Structural Engineering, Vol. 123, No. 10, pp. 1339-1346

[9] Ohno, T. and Nishioka, T. 1984. An Experimental Study on Energy Absorption Capacity of Columns in Reinforced Concrete Structures. Proceedings of the JSCE, Structural Engineering/Earthquake Engineering, Vol. 1, No 2., October pp. 137-147.

[10] Islam, D.S. 2004, Non Linear Finite Element Analysis of Reinforced Concrete Plates in Punching Shear, M. Sc Engineering Thesis, Bangladesh University of Engineering and Technology.

[11] Ahsan, M. S. 2004, Non Linear Finite Element Analysis of Reinforced Concrete Beams with Rectangular Opening', M. Sc. Engineering Thesis, Bangladesh University of Engineering and Technology.

[12] Ahmed, F.S. 2007. Finite Element Analysis of Reinforced Concrete Column under Lateral Load, M. Sc Engineering Thesis, Bangladesh University of Engineering and Technology. 